\title{
Genetic variation in Danaus plexippus L.: Habitat selection or differences in activity times?
}

\author{
M. P. Zalucki*, \\ J. M. Hughes $\dagger$ \\ and P. A. Carterł
}

* Department of Entomology, University of Queensland, St. Lucia, Queensland 4067, Australia.

† School of Australian Environmental Studies, Griffith University, Nathan, Queensland 4111, Australia.

‡ EPO Biology, University of Colorado, Boulder, CO 80309, U.S.A.

Spatial variation in Danaus plexippus (Lepidoptera: Nymphalidae) in south-east Queensland was studied using 2 gene loci, Pgm and Hbdh. Butterflies were sampled from 16 sites on each of two occasions, once in spring on a large spatial scale and again in late summer on a fine spatial scale. Levels of genetic variability, as measured by mean $F_{\text {st }}$ statistics, were lower on both occasions than in a previous study. Significant spatial variation was detected on a fine scale at the Hbdh locus $\left(F_{\text {st }}\right)$, and at both Pgm and Hbdh using spatial autocorrelation statistics. Differences in allele frequencies between sexes were again detected. There was no evidence for habitat selection. An alternative explanation for the spatial variation based on differences in activity times between genotypes is proposed.

\section{INTRODUCTION}

High levels of spatial genetic variation have been reported for a number of organisms (e.g. mussels, Koehn 1978; landsnails, Johnson 1976; black flies, Snyder and Linton 1984; and cicadas, Archie et al., 1985) but such differences have seldom been recorded in situations where the animals move regularly between sampling areas. Some authors (e.g., Ehrlich 1975, Shaklee 1984) have suggested that high levels of movement between sites is sufficient to negate any genetic differences due to selection or drift.

In an earlier study of monarch butterflies in south east Queensland we found high levels of genetic differentiation between closely spaced sites (Hughes and Zalucki, 1984). As monarchs are highly vagile and move freely between closely spaced sites (Zalucki and Kitching, 1985), we suggested that our results reflected differences between genotypes in habitat preferences rather than any differential selection between sites. For example, some genotypes may spend more time around large patches of larval food plant (milkweed) than others. Such differences in behaviour may lead to differences in genotype frequencies between dense and sparse areas of food plant.

An alternative explanation for our results is that there are differences between genotypes in activity times, due to differences in efficiency of their enzymes at temperature extremes. Such differences have been reported for other butterfly species (Watt, 1977) and could lead to the impression of between site differences if sampling was carried out on days with differing weather conditions.

In this paper we examine further the levels of spatial variation in monarchs in south east Queensland using two gene loci, Pgm and $\mathrm{Hbdh}$. Monarchs were sampled from milkweed patches on two occasions: once, on a similar spatial scale to a previous study (Hughes and Zalucki, 1984) but at a different time of year, thus allowing us to compare levels of variation between seasons, and once at the same time of year as the previous study but on a more restricted spatial scale. In the latter survey we chose sites in two categories (milkweed patch or not a milkweed patch) and recorded the temperature and cloud cover at the time of sampling. This information should help to distinguish between the two explanations of the between site variation.

\section{MATERIALS AND METHODS}

\section{Sampling}

The sets of data were collected in September, 1983, and February, 1984. Data set 1 consisted of 16 sites 
in the greater Brisbane area, nine to the south towards Beenleigh, and seven to the west towards Mt Crosby (figs. 1-4). The second sampling was from a more restricted region around Mt Crosby and Kenmore. Again 16 sites were sampled. In each of the 32 sites, butterflies were collected for approximately one man hour, with sample sizes averaging 30 . For the second set other data on the site and local weather conditions were collected. Specimens were kept alive in envelopes until they could be frozen.

\section{Laboratory analysis}

In the laboratory each butterfly was sexed and abdomens were removed and homogenised in $0.5 \mathrm{ml}$ of buffer $(0.02 \mathrm{M}$. Tris, $0.001 \mathrm{M}$. EDTA, $0.01 \mathrm{M}$ Ammonium chloride, $0.1 \mathrm{M}$ Glucose and 0.02 per cent Sodium Azide). They were spun at below $4^{\circ} \mathrm{C}$ at $10000 \mathrm{rpm}$ for 20 minutes in a Sorval RC5B centrifuge. The supernatant was decanted into vials and stored at $-20^{\circ} \mathrm{C}$ until used.

Electrophoresis was performed on cellulose acetate plates (Titan III Helena Laboratories). For Pgm, 0.1 M. Tris citrate $\mathrm{pH} 7.6$ was used as an electrode buffer and for $\mathrm{Hbdh}, 0.1 \mathrm{M}$. Tris glycine $\mathrm{pH} 8.5$ was used.

\section{Spatial autocorrelation}

Spatial autocorrelation statistics such as Moran's I (Sokal and Oden, 1978) can be used to detect positive, negative and/or absence of correlation between neighbouring sites. Correlograms can be used to detect spatial pattern at different scales by connecting sites at various distances apart and calculating the autocorrelation statistic. We constructed correlograms by connecting sampling sites which fell within an annulus centred on each site. The annulus radius was then systematically increased and Moran's I calculated for each set of connections as in Zalucki et al., 1984. The weighting given to each pair of neighbours was set to $1 / d^{2}$ where $d$ is the euclidean distance between a connected pair of sites. This weighting corresponds to a diffusion model for monarch dispersal, with close sites more heavily weighted in the analysis. We treated the frequency of each allele for each sex as an interval variable for each site sampled.

\section{RESULTS}

\section{Between site differentiation}

Table 1 presents $F_{\text {st }}$ values for the first data set collected in September 1983. Overall there were
Table 1 Mean sample size for collection $(\bar{N})$, mean frequency $(\bar{P})$, range and standardised variances $\left(F_{\mathrm{st}}\right)$ for four common alleles in Survey 1, September 1983.

\begin{tabular}{|c|c|c|c|c|}
\hline Allele & $\bar{N}$ & $\bar{P}$ & Range of $P_{l}$ & $F_{\mathrm{st}}$ \\
\hline $\mathrm{HBDH}-\mathrm{S}$ & 30 & 0.75 & $0.67-0.83$ & 0.0052 \\
\hline PGM-F & 31 & 0.29 & $0.11-0.36$ & 0.0054 \\
\hline PGM-M & 31 & 0.39 & $0.29-0.64$ & 0.0116 \\
\hline PGM-S & 31 & 0.32 & $0 \cdot 23-0 \cdot 43$ & 0.0071 \\
\hline \multicolumn{5}{|c|}{$\vec{F}_{\mathrm{st}}=0.0073$} \\
\hline
\end{tabular}

no significant $F_{s t}$ values, indicating that gene frequencies were similar across sites. As we had found sex differences previously we calculated separate $F_{\mathrm{st}}$ values for males and females. To do this, nearby sites were pooled as shown in table 2 . There was no significant differentiation between localities for either sex. Also there were no significant differences between sexes (figs. 1 and 2).

Table $2 F_{\text {st }}$ values for males and females collected in Septem. ber 1983. Sites were pooled into 4 groups: $1(19-24), 2(27-$ $29), 3(30-33), 4(25,34,35)$. See fig. 1.

\begin{tabular}{lllll} 
& \multicolumn{2}{c}{ Males } & \multicolumn{2}{c}{ Females } \\
\cline { 2 - 5 } & $F_{\text {st }}$ & $\chi^{2}$ & $F_{\text {st }}$ & $\chi^{2}$ \\
Pgm-F & 0.0008 & 0.70 & 0.0007 & 0.47 \\
Pgm-M & 0.0032 & 2.97 & 0.0031 & 2.73 \\
Pgm-S & 0.0018 & 1.67 & 0.0023 & 2.11 \\
Hbdh-F & 0.0022 & 1.88 & 0.0004 & 0.32 \\
\hline
\end{tabular}

For the second data set collected in February 1984 , there was a significant $F_{\text {st }}$ value for $\mathrm{Hbdh}$ but not for Pgm (table 3). The 16 sites in this data set were collected from a relatively small geographic area (fig. 3) and the significant $F_{\text {st }}$ value indicates spatial variation on a fine scale. Separate $F_{\text {st }}$ values were calculated for males and females by pooling nearby sites (table 4 ). Significant values were found for Hbdh-F in females (table 4). There were significant differences in genotype frequencies between males and females $\left(x^{2}=18.34, p<\right.$ 0.01 ) for the Pgm locus (table 5).

Table 3 Mean simple per collection $(\bar{N})$, mean frequency $(\bar{P})$, range and standardised variances $\left(F_{s t}\right)$ for four common alleles for Survey 2, February $1984(p<0.05)$.

\begin{tabular}{lllll}
\hline Allele & $\bar{N}$ & $\bar{P}$ & Range of $P_{t}$ & \multicolumn{1}{c}{$F_{\text {st }}$} \\
\hline HBDH-S & 29 & 0.80 & $0.70-0.88$ & $0.0085^{*}$ \\
PGM-F & 29 & 0.30 & $0.19-0.38$ & 0.0061 \\
PGM-M & 29 & 0.40 & $0.28-0.50$ & 0.0033 \\
PGM-S & 29 & 0.30 & $0.23-0.50$ & 0.0082 \\
& & & & $\bar{F}_{\mathrm{st}}=0.0065$ \\
\hline
\end{tabular}




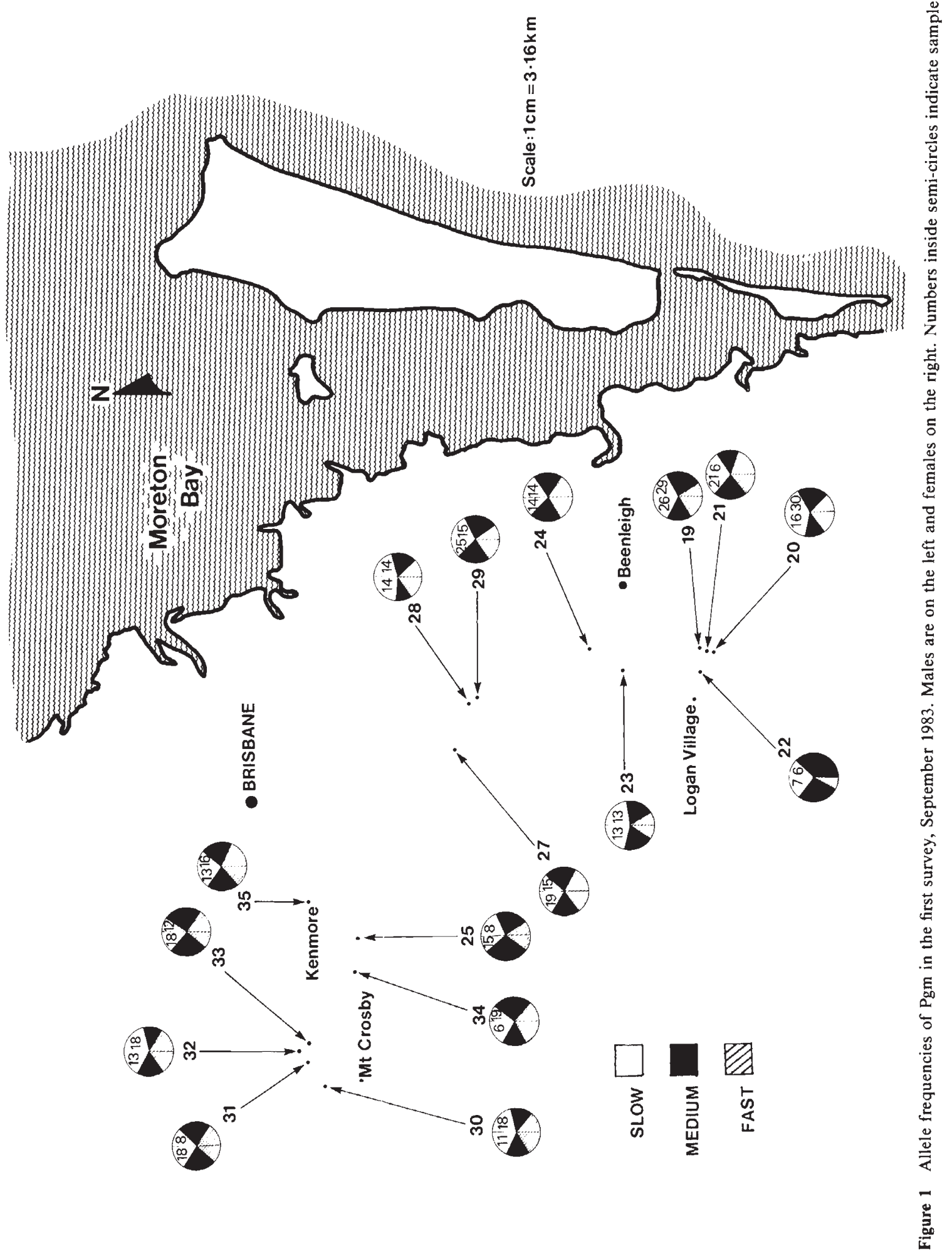




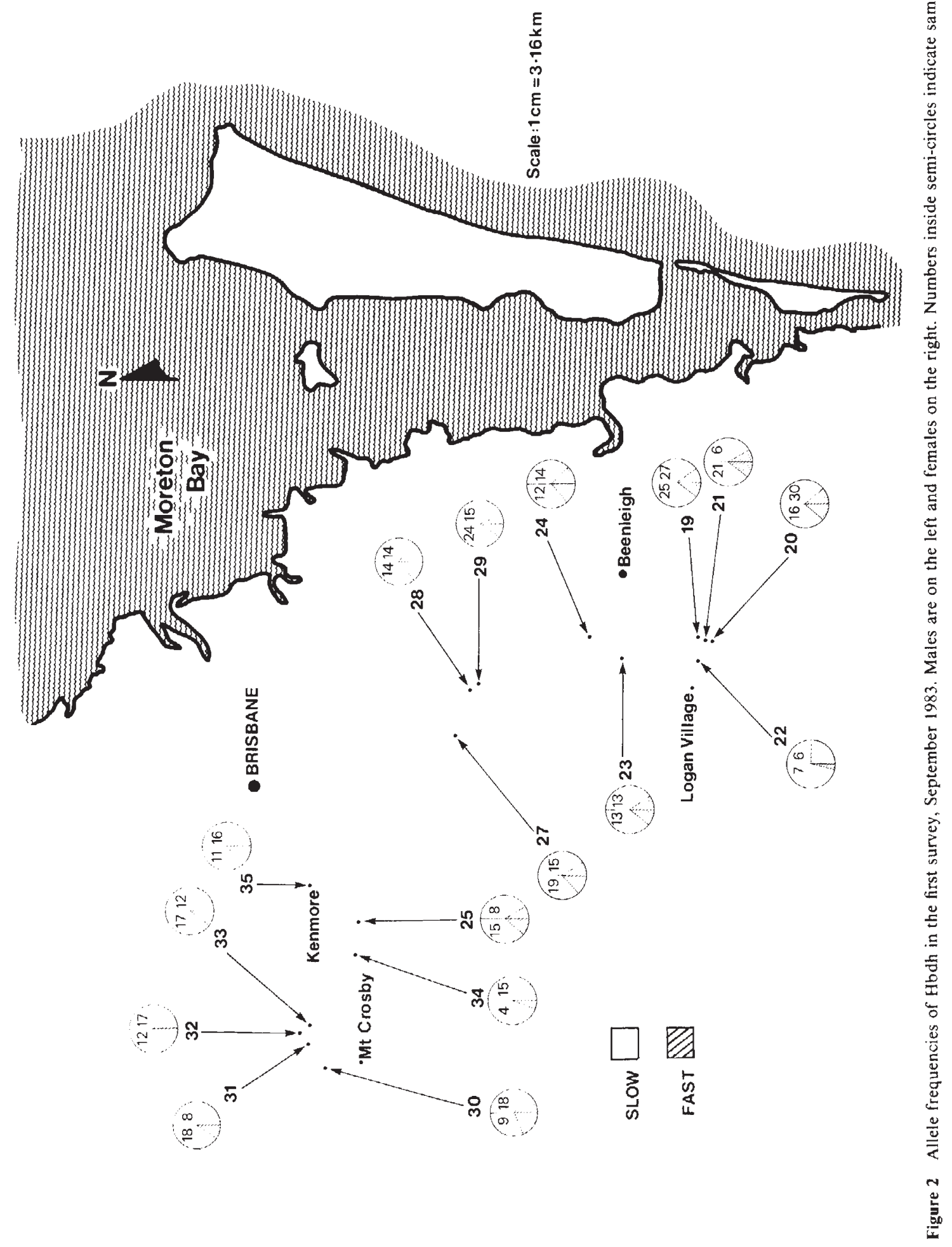




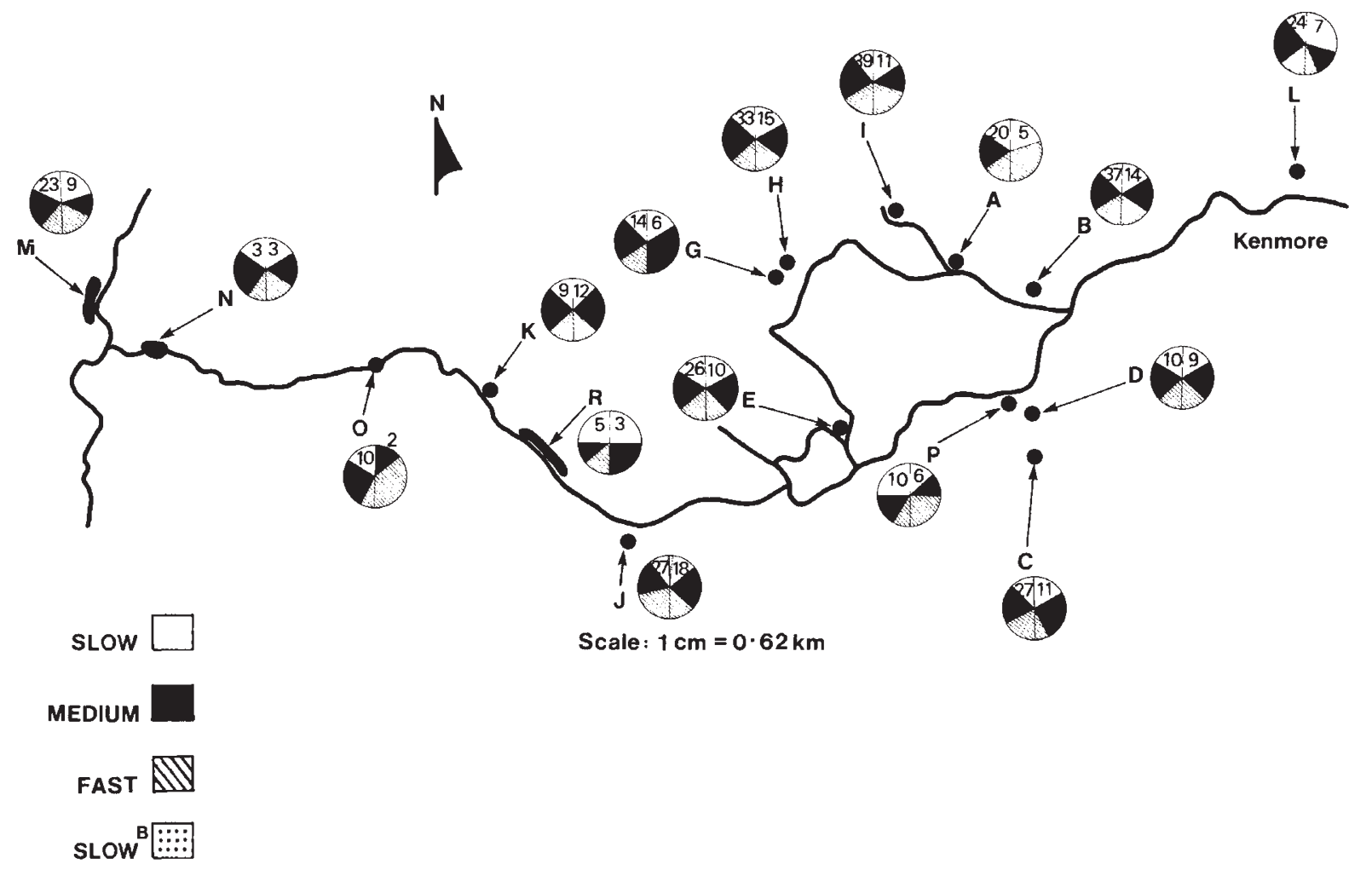

Figure 3 Allele frequencies of Pgm in the second survey, February 1984. Males are on the left, females on the right. Numbers inside semi-circles represent sample sizes.

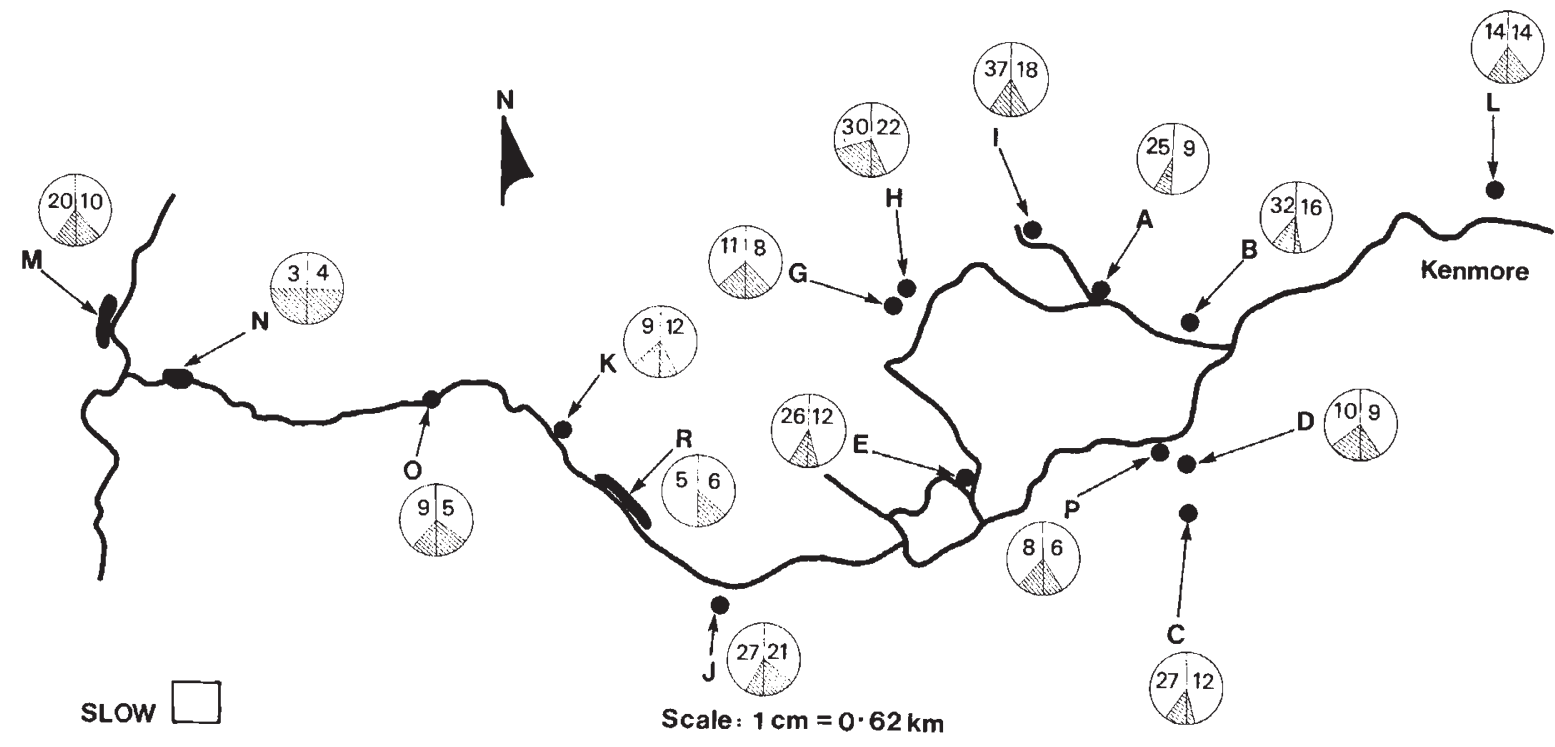

\section{FAST MIV}

Figure 4 Allele frequencies of Hbdh in the second survey, February 1984. Males are on the left and females on the right. Numbers inside semi-circles represent sample sizes. 
Table $4 F_{\text {st }}$ values for males and females February 1984. Sites were pooled into 5 groups: $1(\mathrm{M} \& \mathrm{~N}), 2(\mathrm{~J}, \mathrm{~K}, \mathrm{O}, \mathrm{R})$, $3(\mathrm{~A}, \mathrm{~B}, \mathrm{I}, \mathrm{H}, \mathrm{G}), 4(\mathrm{C}, \mathrm{D}, \mathrm{P}, \mathrm{E})$ and $5(\mathrm{~L}) .\left({ }^{*} p<0.05\right)$

\begin{tabular}{llclc}
\hline & \multicolumn{2}{c}{ Males } & \multicolumn{2}{c}{ Females } \\
\hline & $F_{\text {st }}$ & $\chi^{2}$ & $F_{\text {s1 }}$ & $\chi^{2}$ \\
Pgm-F & 0.0020 & 2.49 & 0.0064 & 3.70 \\
Pgm-M & 0.0009 & 1.19 & 0.0072 & 4.18 \\
Pgm-S & 0.0017 & 2.20 & 0.0082 & 4.73 \\
Hbdh-F & 0.0032 & 3.71 & 0.0167 & $12.03^{*}$ \\
\hline
\end{tabular}

Table 5 Genotype frequencies for males and females, February 1984. Pgm: $\chi_{(5)}^{2}=18 \cdot 34$, $p<0.01$, Hbdh: $\chi_{(2)}^{2}=3.49$, n.s.

\begin{tabular}{lll}
\hline Pgm & Males & Females \\
\hline SS & 0.05 & 0.11 \\
SM & 0.28 & 0.26 \\
SF & 0.20 & 0.16 \\
MM & 0.08 & 0.13 \\
MF & 0.35 & 0.24 \\
FF & 0.03 & 0.09 \\
Sample size & 318 & 140 \\
Hbdh & Males & Females \\
SS & 0.62 & 0.69 \\
SF & 0.32 & 0.27 \\
FF & 0.06 & 0.03 \\
Sample size & 291 & 180 \\
\hline
\end{tabular}

\section{Spatial autocorrelation}

To further define the scale and nature of the spatial genetic variation we used spatial autocorrelation techniques. Correlograms were constructed for each allele for each sex for data sets 1 and 2 . Analysis of the first data set revealed no significant correlation between neighbouring sites at any spatial scale. Substantially the same result was obtained for the second data set (figs. 5-7) with random distribution of allele frequencies at most spatial scales, but there were some notable exceptions. Nearby sites (within $3.1 \pm 3.1 \mathrm{~km}$ ) were significantly $(p<0.05)$ negatively autocorrelated for the Pgm-S allele in males (fig. 5); that is, nearby sites have significantly different $\mathrm{Pgm}-\mathrm{S}$ frequencies. In females the Pgm-F allele frequencies were significantly positively autocorrelated at long distances $(9.3 \pm 3.1 \mathrm{~km}$, fig. 6). For the Hbdh-F locus, males and females again show a different pattern of spatial arrangement, with frequencies being randomly distributed by site in males, but a significant negative autocorrelation was detected for distantly $(9.3 \pm 3.1 \mathrm{~km})$ connected sites for females (fig. 7).

As the butterflies are quite mobile and fly freely between closely spaced sites (Zalucki and Kitch- ing, 1985) we considered that geographic separation was unlikely to be affecting allele frequencies. In other words, we are probably looking at subsets of a single population. Two possible explanations of the observed patterns were considered: first, the differences may be due to different habitat preferences of the butterflies with variation between different types of milkweed patch; e.g., those with densely packed plants and those where the plants are only sparsely distributed. Second, the differences could be due to variation in activity times between genotypes, and as the weather conditions and time of day of sampling varied considerably between sites, the results may reflect these differences, rather than real spatial differences.

\section{Habitat preference}

To examine if differences were due to differences between habitat types, sampling sites were placed into one of two categories, either "patch", where the milkweed was fairly dense, and "non-patch" where plants were very sparse (kess than 1 plant per $\mathrm{m}^{2}$ ). Contingency table analysis (separately for males and females) showed no differences in genotype frequencies between patches and nonpatches. When comparisons between specific genotypes were made between patches and nonpatches (using tests of proportions, Freund, 1979) some differences were found, both in males and females (table 6). For Pgm the SM genotype in males was more common in non-patch sites $(p<$ $0.05)$. Also the frequency of the SF genotype in Hbdh was higher in non-patches relative to patches in females $(p<0.05)$, but the reverse was the case in males (although this difference was not significant-see table 6).

\section{Effect of weather}

When sites were pooled according to weather conditions at the time of sampling (table 7), contingency table analysis again showed no significant effect of weather conditions on genotype frequencies $(p>0.05)$. Tests of proportions showed that at the Pgm locus, the frequency of the SM genotype in males was higher in samples collected on fine hot days than on cool cloudy days. In females a significant difference was observed in $\mathrm{MF}$ and FF frequencies. At the $\mathrm{Hbdh}$ locus there was no significant difference between samples in males, but in females there was a significantly higher frequency of the FS genotypes in samples collected in hot conditions than in those collected in cool conditions. 


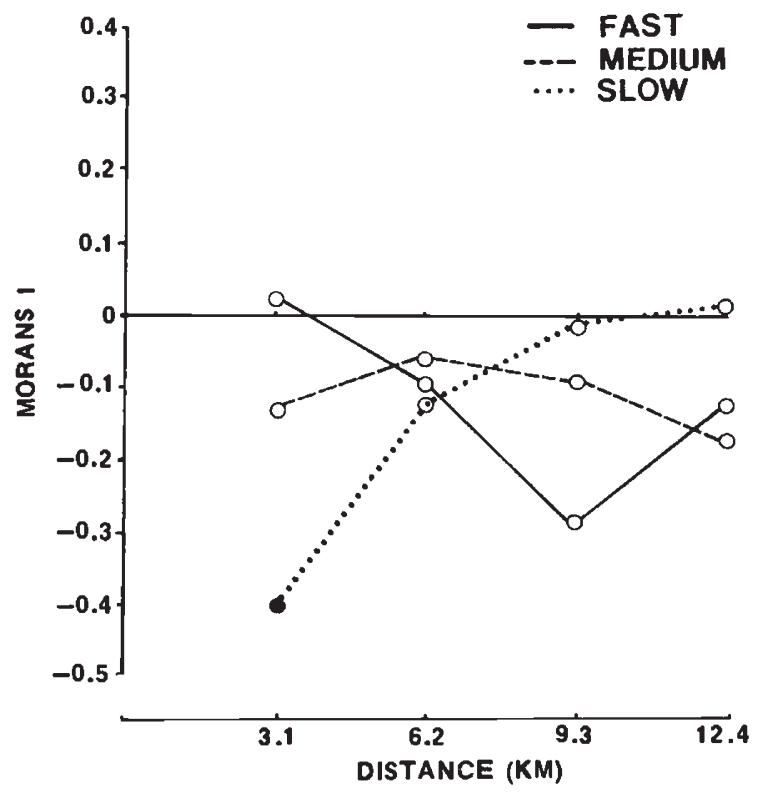

Figure 5

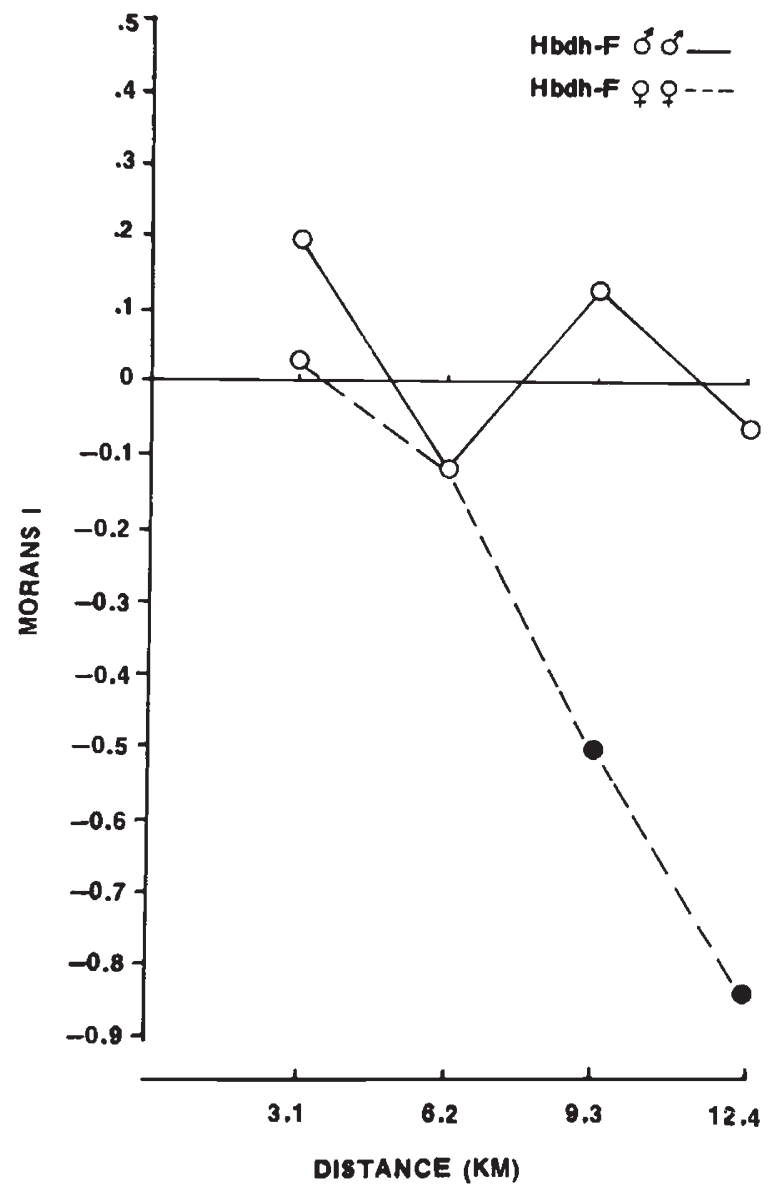

Figure 7

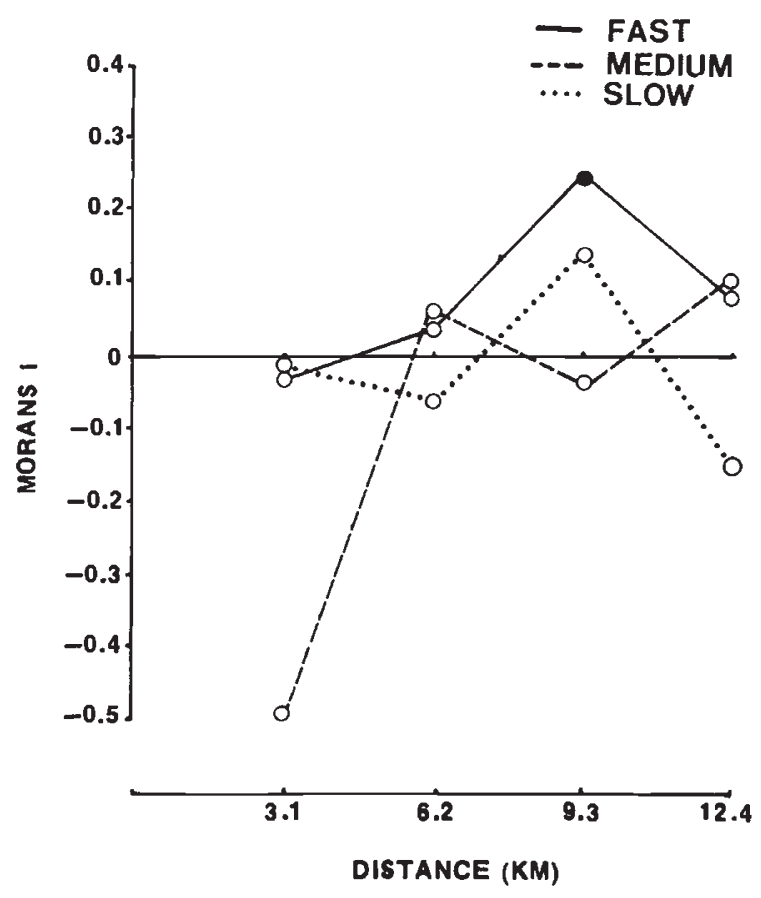

Figure 6

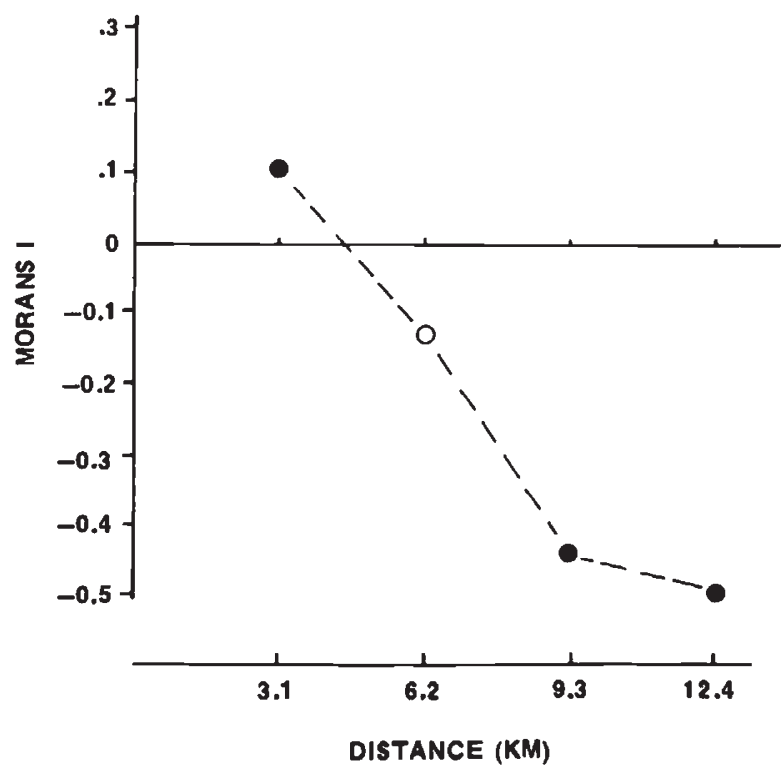

Figure 8

Figures 5-8 Correlogram plots of Morans I versus Euclidean distance between neighbouring patch sites (see text for details) for Pgm: males (fig. 5) and females (fig. 6), Hbdh-F males and females (fig. 7) and sites classified by weather conditions on the sampling day (fig. 8). Solid symbols (O) indicate significant deviation $(p<0.05)$ of Morans I from zero, open symbols $(O)$, no significant difference. 
Spatial autocorrelation analysis revealed there is significant geographic pattern in gene frequencies for both Pgm and Hbdh in the second sample. This sample of 16 sites was taken in a relatively small geographic area (figs. 3,4 ). Such fine scale variation in what is a highly vagile animal (Zalucki and Kitching, 1985) could be due to either habitat selection (see also Powell and Taylor, 1979) or weather selection (see also Watt, 1983; Watt et al., 1983).

Zalucki and Suzuki (1987) in a study of the effects of patch type on adult monarch population parameters, showed that the largest differences occurred when comparing patches and nonpatches. Although in this study there were no overall effects of habitat type on genotype frequencies there were differences in specific genotypes so habitat selection cannot be ruled out entirely. Similarly for the effects of weather, there was no overall effect but some differences were found in specific genotypes. Some of the spatial pattern in the Hdbh-F allele could be due to weather effects; however, this is not the case for Pgm.

The non-sex-linked differences in gene frequency (Hughes and Zalucki, 1984) were confirmed in the second sample of this study. Theoretical studies (e.g., Mandel, 1971; Kidwell et al., 1977) have indicated how such a result might be explained if natural selection acted differently on males and females. Habitat and weather selection could also differ between males and females. If this were the case, we would expect the sex differences to reverse in alternate habitats/weather conditions. This was observed in some cases but not others (see Results). Our analyses indicate that weather conditions at the time of collection differentially influenced frequencies of particular genotypes in males and females. This result could explain both the spatial and sex variation reported in Hughes and Zalucki (1984). In that study we sampled sites within localities on the same day but of necessity at different times of the day. If, as we suggest, different genotypes are active at different times of the day, then our samples would be biased according to the time of day and the weather conditions in which they were collected. The between locality variation would appear to be higher than it really is.

Acknowledgements This study was funded by grants from ARGS, the Ian Potter Foundation, University of Queensland and Griffith University. We wish to thank Warren Brown,
Duncan Mackay, Yoshito Suzuki, David Morgan and Chris Fitzgerald for technical and field assistance, Paula Coutts for help with figures and Vicki McMahon for typing the manuscript.

\section{REFERENCES}

ARCHIE, J., SIMON, C. AND WARTENBERG, D. 1985. Geographical patterns and population structure in periodical acadas based on spatial analysis of allozyme frequencies. Evolution, 39, 1261-1274.

EHRLICH, P. R. 1975. The population biology of coral reef fishes. ¿inn. Rev. Ecol. Syst., 6, 211-247.

FREUND, J. E. 1979. Modern Elementary Statistics, Prentice Hall, London.

HUGHES, J. M. AND ZALUCKI, M. P. 1984. Genetic variation in a continuously breeding population of Danaus plexippus L. (Lepidoptera: Nymaphalidae). Heredity, 52, 1-7.

JOHNSON, M.S. 1976. Allozymes and area effects on the Western Berkshire downs. Heredity, 36, 105121.

KIDWELL, J. F., CLEGG, M. T., STEWARD, F. M. AND PROUT, T. 1977. Regions of stable equilibria for models of differential selection in two sexes under random mating. Genetics, $85,171-183$.

KOEHN, R. K. 1978. Physiology and biochemistry of enzyme variation: the interface of ecology and population genetics. Brussard (ed.) In Ecological Genetics: The Interface, Springer-Verlag, New York.

MANDEL, S. P. H. 1971. Owen's model of a genetical system with differential viability between the sexes. Heredity, 26, 49-63.

POWELL, J. R. AND TAYLOR, G. E. 1979. Genetic variation in ecologically diverse environments. Am. Sci., 87, 390-398.

SHAKLEE, J. B. 1984. Genetic variation and population structure in the damselfish, Stegastes fasciolatus, throughout the Hawaiian Archipelago Copeia 1984: 629-640.

SNYDER, T. P. AND LINTON, M. C. 1984. Population structure in black flies: allozymic and morphological estimates for Prosimulium mixtrum and $P$. fuscum (Diptera: Simuliidae). Evolution, 38, 942-956.

SOKAL, R. R. AND ODEN, N. L. 1978. Spatial autocorrelation in biology 1. Methodology. J. Linn. Soc (Biol), 10, 199-228.

WATT, W. B. 1977. Adaption at specific loci. I. Natural Selection on phosphoglucose isomerase of Colias Butterflies: biochemical and population aspects. Genetics, 87, 177-194.

WATT, W. B. 1983. Adaptation at specific loci. II. Demographic and biochemical elements in the maintenance of the Colias PGI polymorphism. Genetics, 103, 691-724.

WATT, W. B., CASSIN, R. C. AND SWAN, M. S. 1983. Adaptation at specific loci. III. Field behaviour and survivorship differences among Colias PGI genotypes are predictable from in vitro biochemistry. Genetics, 103, 725-739.

ZALUCKI. M. P., DREW, R. A. I. AND HOOPER, G. H. S. 1984 Ecological studies of Eastern Australian fruit flies (Diptera: Tephutidae) in their endemic habitat II The spatial pattern of abundance. Oecologia, 64, 273-279.

ZALUCKI, M. P. AND KITCHING, R. L. 1985. The dynamics of adult Danaus plexippus $\mathrm{L}$. within patches of its food plant, Asclepias spp. J. Lep. Soc, 38, 209-219.

ZALUCKI, M. P. AND SUZUKI, Y. 1987. Milkweed patch quality, adult population structure and egg laying in Danaus plexip pus (Lepidoptera: Nymphalidae). J. Lep. Soc. (in press). 